\title{
Journal of Global Awareness
}

Volume 1

Number 1 Inaugural Issue of the Journal of

Global Awareness

August 2020

\section{Combatting COVID-19 in Hungary}

Marietta Pókay

University of Pécs

\section{Recommended Citation}

Pókay, Marietta (2020) "Combatting COVID-19 in Hungary," Journal of Global Awareness: Vol. 1: No. 1, Article 5.

Available at: https://scholar.stjohns.edu/jga/vol1/iss1/5

This Article is brought to you for free and open access by St. John's Scholar. It has been accepted for inclusion in Journal of Global Awareness by an authorized editor of St. John's Scholar. For more information, please contact karniks@stjohns.edu, fuchsc@stjohns.edu, fazzinol@stjohns.edu. 


\begin{abstract}
2020 has witnessed an allegedly unprecedented situation by the outbreak of the new coronavirus pandemic. Some countries are hit more harshly by COVID-19 than others, but we all suffer the medical, economic, and social consequences, although to various extent. Hungary does not perform badly in managing the situation. This article briefly describes how Hungary handles the healthcare and economic issues raised by this pandemic.
\end{abstract}

Keywords: pandemic, coronavirus, healthcare service provision, economic recession, and economic recovery

\title{
Introduction
}

We are facing an unprecedented situation these days. This is an often-used statement in public discourse. But is it true? Not really. Neither viruses (of course, not this new one) nor pandemics are unknown even for members of the public. One should think of the Spanish Influenza in 1918-1919 demanding more victims than the First World War itself or the plague, cholera, and typhoid epidemics sweeping across Europe for centuries. The Black Death may have existed in Europe as early as $3.000 \mathrm{BC}$, but its fatal occurrence was the pandemic of $1348-1353$, causing the death of $30-50 \%$ of the population in Europe. Even the $21^{\text {st }}$ century has witnessed some pandemics like the severe acute respiratory syndrome (SARS) emerging from China's Guangdong province in November 2002, the 2009 H1N1 flu pandemic, also known as the swine flu, the Middle East respiratory syndrome (MERS), the most widespread outbreak of Ebola between 2013 and 2016, and the Avian flu (bird flu), which has not (yet) reached pandemic levels according to WHO.

What is unprecedented, though, is how we tackle the situation although some of its elements such as isolation of the infected, quarantine, lockdown of geographical areas, improved personal hygiene, protective gear, and equipment, also some of its consequences such as high death toll, economic downturn, and occasional social disturbances have characterized all previous instances of pandemics.

\section{How it Began}

The first case of COVID-19 was identified in Wuhan, China, originating from a market called Huanan, selling fish and games. China reported the cases of mysterious viral pneumonia to the WHO on December 31. Chinese authorities identified a new coronavirus causing the disease on January 7. Since then, it has rapidly spread to all inhabited continents, and there are fears that the virus might have been transmitted to the International Space Station when a Soyuz rocket launched a new crew on April 9. The WHO admitted the situation might be of 
international concern on January 30 but did not officially use the term pandemic before

March 11 2020. The first three confirmed cases in Europe (France) were reported on January 24 to the WHO Regional Office for Europe.

The disease hit Hungary on March 4, on March 11 the government declared a state of emergency. "These measures are unprecedented in the three decades since the fall of communism," according to Gergely Gulyas, the minister in charge of the prime minister's office. The first COVID-19-related death was announced on March 15, and by March 18, the pandemic had spread to every part of the country.

Hungary had a national pandemic response plan in place before the outbreak of this new pandemic, but it was specific to pandemic influenza. It was created in 2009 when the H1N1 appeared. The content was the following: impact of the pandemic on the society, on the health system and the economy; organizations and the legal framework of their work in the preparedness for the pandemic and the eradication of pandemic; the phases of the pandemic.

On March 30, the National Assembly adopted Act XII of 2020 on the containment of coronavirus that practically allowed Prime Minister Orbán to rule by decree without any time constraints, although officially during the emergency and for the purposes of tackling it. This act met fierce criticisms, mainly from the political opposition, primarily due to the indefinite period of the state of emergency, but finally, Vera Jourova, European Commission vicepresident, stated no provision of the said act was in conflict with European regulation. Still, there are well-grounded concerns regarding the legality, legitimacy, and democratic nature of sometimes really tough measures. Is it worth taking and observing them? How effectively do they protect the life of our fellow citizens? There are plenty of indicators showing it; one of the most convincing may be the ratio of the number of COVID-19-related deaths to the population. According to data from Johns Hopkins University, the number of deaths attributable to the new coronavirus was 2.45 per 100,000 persons. It was over 40 in Italy and Spain and over 50 in Belgium.

It seems Hungary performs quite well in this respect compared to other major EU countries and the UK. One reason for this could be the early and swift response to the situation and the fact that Hungary could learn the lessons from the example of countries stricken harshly by the pandemic such as China or Italy. The rest of the article summarizes how Hungary combats COVID-19 and how it tries to mitigate the damaging economic and social effects of the pandemic. 


\section{Healthcare Governance}

The national response to the situation is led by the government supported by a so-called Operational Group, jointly led by the Minister of Interior and the Minister of Human Capacities, with representatives of relevant organizations, such as the national Chief Medical Officer. The measures to be introduced are announced in daily press conferences except those with strategic importance, which are communicated by the Prime Minister. As part of the emergency measures, hospital commanders were appointed to 108 inpatient care institutions on March 29. Hospital commanders do not have competence over healthcare issues; their task is to ensure the necessary medical supplies and equipment and the smooth flow of information to the Operational Group. In addition, mayors are empowered to introduce special measures concerning combatting COVID-19, such as imposing stricter rules on movement, wearing masks in public places, and on means of public transport, opening hours of shops and markets, etc.

Border control to Austria and Slovenia was reinstated, and border crossing from the outbreak countries (South Korea, Italy) was no longer allowed. Since March 12, essential healthcare workers (physicians, nurses, and other healthcare professionals) were asked to stay in the country and return from abroad. From March 16, the borders were closed for passenger transportation, and Hungarian citizens entering the territory of Hungary from abroad are obliged to undergo a medical examination. Depending on the outcome of the examination, they are subjected to different types of quarantine. This decision allowed a humanitarian passage to remain open for foreign individuals passing through.

\section{Slowing Down the Transmission of the Virus}

Newly introduced measures are aimed at flattening the curve of the spread of coronavirus to avoid overwhelming the capacity of medical facilities and medical staff and preparing the country for the worst scenario of the development of the situation. The main areas are isolation, increased personal hygiene and cleaning surfaces, social distancing, and avoidance of gatherings. In addition, there are special rules to protect the most vulnerable groups, senior citizens (aged over 65), those with chronic diseases (e.g., cardiovascular disease, diabetes, chronic respiratory disease, hypertension, cancer), and those living in big cities. To this end, stricter and stricter measures have been introduced week by week since March 4. Comprehensive restrictive measures are essential as approximately $80 \%$ of those having contracted the new coronavirus show only mild or even no symptoms at all. However, they are all virus carriers thus can infect others.

Those diagnosed with COVID-19 have to be quarantined in St. László Hospital, the center for Hungary's infectious diseases, or one of the four other designated hospitals. Those who are suspected carriers of the virus, who have been in direct 
contact with infected patients who have returned to Hungary from virus-stricken areas, have to stay in home quarantine. People with symptoms or who have an active respiratory illness are asked to phone their GP instead of turning to a medical facility for a consultation. Testing for the coronavirus is performed in one of the ten designated, accredited laboratories. Answering criticisms concerning the low number of such tests, the Chief Medical Officer pointed out that the WHO representative finds testing in Hungary professionally adequate.

First universities were closed, but now secondary and primary schools and kindergartens are closed, education is continuing online at all levels. Daycare is provided only for those whose parents are essential workers. All events and gatherings are prohibited as of March 27. Most traditional churches in Hungary decided to suspend regular religious gatherings (but continued services online). Teleworking, working from home, i.e., "home office" is encouraged in all workplaces. Shops, except those selling food, tobacco, and medicine, can stay open only until 3 p.m.; cultural facilities are closed just like restaurants, which can only serve for delivery or take-away. Citizens over 65 can do their shopping only between 9 and 12; at this time, younger persons cannot enter the shops, pharmacies, or markets. On March 27 a quasi-curfew restriction was introduced, which means that people have to stay at home except for going out to work and shopping for necessities, but they have to keep a social distance of 1.5 meters at public places. These measures are revised weekly. Nursing homes are given special attention; new provisions include prohibiting visits and new admissions, as well as introducing a curfew. Additionally, each nursing home should appoint a person responsible for the prevention of COVID-19.

\section{Provision of Medical Services}

Most hospitals nationwide are deferring elective procedures, including surgeries, examinations, and rehabilitation treatments, and only perform emergency procedures. Oncology is the only branch of medicine exempt. The government has started to expand hospital capacities for both the isolation of suspected cases and the treatment of COVID-19 patients. At the beginning of March, one of the buildings, under the renovation, of a Budapest hospital was repurposed for the isolation of suspected COVID-19 cases. On March 16, the building of a temporary (container) hospital began at Kiskunhalas. A 330-bed capacity temporary facility was established in Budapest in the exhibition buildings of Hungexpo, the biggest company in Hungary organizing exhibitions, international fairs, and conferences. Hospitals all over the country have been required to increase their bed capacity for COVID-19 patients in preparation for the acceleration phase of the epidemic. $50 \%$ of all hospital beds are, and a further $10 \%$ will be freed for this purpose by relocating, in reality, by sending home patients so far receiving treatment there. The Minister for Human Capacities has removed two hospital directors for not complying with the measures: the head of the Fejér County Hospital on April 11 and the head of the National Institute of Medical Rehabilitation on April 12. These measures 
triggered serious concerns about the long-term effects on patients suffering from diseases other than the coronavirus infection. Some experts say more persons will die of such consequences than of COVID-19. Dentists are allowed to perform only emergency care. Certain restrictions on the prescription of pharmaceuticals have been removed; ePrescriptions are available and can be redeemed by anyone on behalf of the patient since March 13.

The availability of personal protective equipment, like masks, gloves, goggles, protective clothing, tests, and breathing apparatuses, is vital for preventing the transmission of the virus and treating patients with severe respiratory difficulties. Since the outbreak of the pandemic, there has been a race for such products. Like other EU countries, Hungary has purchased most of such equipment from China. However, consignments have also arrived from Turkey and Uzbekistan as Hungary has turned to the Turkic Council for help. Solidarity is manifest in the other direction too; Hungary has sent medical equipment to the neighboring countries with citizens of Hungarian ethnic origin and to countries in the West-Balkan.

Naturally, the demand for responsible and skilled health workforce has also increased. Doctors, nurses, and all others working in healthcare play a pivotal role in providing medical services. Those over 65 are exempt from activities that require direct contact with patients. At the same time, medical residents and medical students in their final years are involved in dealing with COVID-19 patients together with doctors of other specialisms if needed. The Ministry of Human Capacities started recruiting volunteer healthcare workers between the ages of 18 and 49 (e.g., students, health professionals from the private sector). Healthcare workers travel free on regional and in several towns on local public transport. Several services have been launched at Semmelweis University (the leading medical university in Hungary) to provide psychological support to frontline health and social workers (Call for Helplines 0-24). The government announced on April 4 that those working in healthcare would get a one-time extra payment of HUF 500,000 gross (about two-month average salary in middle ranks), expected sometime in early Summer, possibly in June.

\section{Who Pays the Expenses?}

On April 4, the government announced the establishment of a Disease Control Fund. They will transfer HUF 663 billion to contain the coronavirus epidemic; Gergely Gulyas, the minister in charge of the Prime Minister's office, said, "The government is initiating a significant reorganization of the budget, and will force others to contribute with burden-sharing. This includes political parties, international firms, banks, and municipalities." Hungary's healthcare system is organized by the National Health Insurance Fund, to which both employees and employers pay contributions. Health insurance coverage is universal, and is free for children, students, pensioners (everyone over 62), unemployed, and the 
disabled. Therefore, the necessary treatment for COVID-19 is available for all ordinarily resident in the country. The European Health Insurance Card is also accepted for emergencies. Hungary will also benefit from the reallocation of EU funds.

\section{Economy}

\section{Economic Downturn}

Due to the spread of COVID-19 and the devastating effects of the global enclosure, we are informed of dramatic measures taken, the termination of manufacturing, the closing down of plants, businesses, and shops, mass dismissals, and profit warnings in Europe and beyond. The worst economic effects of the pandemic in Europe are as follows. In the first phase, authorities tried to trace the chain of the coronavirus infection, but no further measures were taken. Tourism, catering, and transport services suffered the consequences of people becoming more cautious. In the second phase, when governments realized that mass infection could not be avoided, and territorial and personal quarantining, restrictions on movement have a serious impact on the economy. The measures taken to slow down the spread have led to the closure of factories, the termination of services, difficulties in supply provision, and the breaking of supply chains, endangering businesses beyond the tourist industry. Prolonged insecurity, the deterioration of faith and trust in the world of business, can decrease the demand for consumption and investment and can lead to a further, broader economic recession. The growth of productivity can be blocked; companies can get unstable and even get close to insolvency.

Hungary has also suffered similar consequences of the pandemic. According to analysts, the new coronavirus can have dramatic economic effects in Hungary. Some of these are as follows.

- Tourism, catering, and other actors of the service industry linked to them suffer huge losses.

- Jobs are terminated; the government expects to have job losses amounting to hundreds of thousands. As of April 24, the number of unemployed has increased by 51 thousand, and the number of vacant positions has decreased from 83 thousand to 41 thousand.

- Manufacturing has stopped in three major automobile factories (Mercedes, Audi, Suzuki), which generate a substantial part of GDP. This has adversely affected the companies' suppliers.

- The value of the Hungarian forint has fallen dramatically; the exchange rate changed from HUF 335 to HUF 360 to the euro in a few days.

- The building industry gets into a difficult situation; even huge projects can be delayed. 
Hungary performs relatively well in comparison to other EU member states in terms of economy. IMF forecasts Hungary will have the second smallest economic drop in the EU after Malta.

The changes in some essential indicators of the Hungarian economy are illustrated in Figure 1.

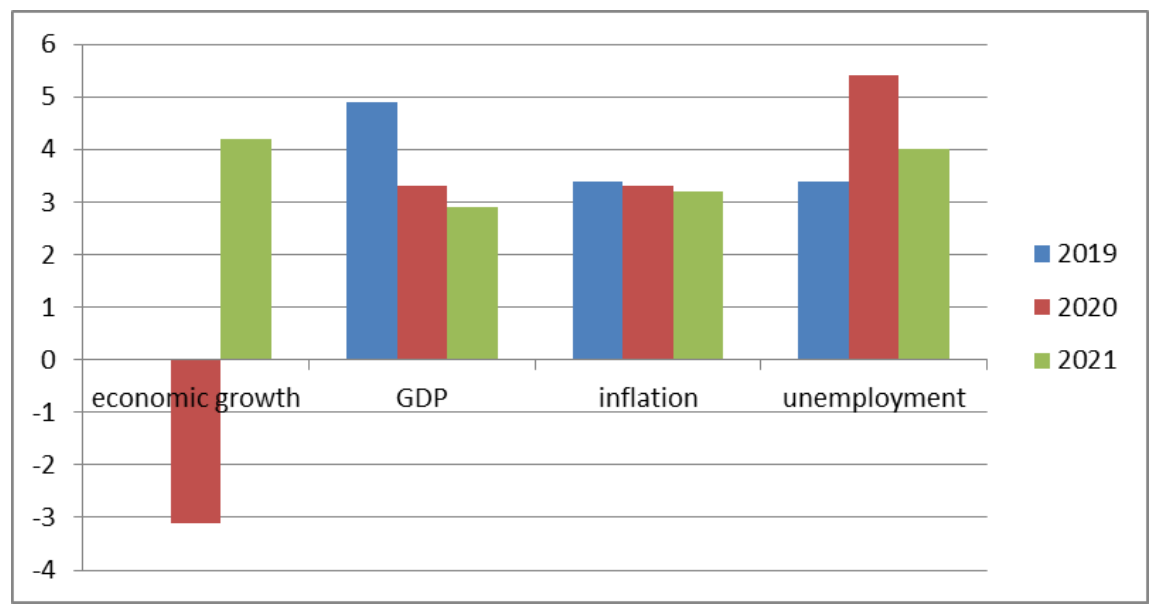

Data taken from https://hungarytoday.hu/imf-forecast-hungary-gdp-2020/

However, Nigel Rendell, an economist with London-based Medley Global Advisors, warned, "If the [COVID-19] virus is long-lasting, for much of the rest of the year, then I don't think anyone knows just how badly growth forecasts could be slashed, neither for the global economy in general, nor Hungary in particular."[1]

\section{Protective Measures}

Several extraordinary measures have been announced to protect the economy. The most important interventions are the following. [2]

- Moratorium on payments of loans for individuals and businesses until the end of the year.

- Over 81,000 small businesses will have an exemption from the tax of small businesses until the end of June.

- Businesses in 11 professions, mainly in tourism, food and beverage services, and media services, are not required to pay contributions, and their employees are allowed to pay reduced taxes.

- In sectors such as tourism, food and beverage services, the entertainment industry, and sport services, the employer is exempted from paying tax and other contributions after the employees in March, April, May, and June. 
- State salary supplement for those working in shortened working hours. The state will pay $70 \%$ of the "lost" wages for three months.

- HUF 450 billion will be devoted to investments for job creation.

- $18-20 \%$ of GDP will be refocused to drive these efforts.

- Online training will be organized for workers amid the shutdowns..

A Fund for the Protection and Restart of the Economy will also be set up. According to Prime Minister Viktor Orban, Hungary will work on a multibillion euro crisis fund to help industries affected by the coronavirus. In total, HUF 1,345 billion will be available in the fund.

There are plans in the EU to help the recovery of the economies of member states e.g., issuing bonds, borrowing, or establishing a special fund. This latter is the most likely to happen. Everything is yet to be decided, and money cannot be used to stimulate the economy of members' states before 2022, experts say.

\section{Social Effects}

"The COVID-19 outbreak affects all segments of the population and is particularly detrimental to members of those social groups in the most vulnerable situations, continues to affect populations, including people living in poverty situations, older persons, persons with disabilities, youth, and indigenous peoples" [3], warns the UN Department of Economic and Social Affairs. Incidents of social disturbance, increased domestic violence have been reported in many countries, also in the EU. Indeed, Hungary has also witnessed detrimental social effects of the pandemic, although no incidents of public disturbances or demonstrations of any kind. Everybody, individuals, and enterprises alike will suffer the negative consequences of the pandemic; still, increasing unemployment and the downturn of the economy will strike more harshly those without substantial reserves or living near or below the poverty line. The government intends to create as many jobs as having been lost due to the virus. Criticisms have been raised saying the government should directly help those in difficult financial situations; immediate monetary assistance should be far more substantial. Due to its commitment to a "labor-based economy," the government still prefers job creation and the support of enterprises to the allocation of financial aids to individuals.

However, following the initial insecurity, uncertainty, and hesitation, people tend to strengthen their self-confidence and trust in being able to cope with the situation. At the same time, a sense of solidarity, willingness to help others, and do voluntary work has gradually developed. Although official publications, commercials, and even rules, for instance, instructing municipalities to help the elderly and others in need, if there are no relatives or neighbors to do so, social 
media exert the most significant impact. Good examples and practices, farreaching and small-scale civic initiatives alike find their way to all strata of the society. One can only hope this attitude will not change when the devastating economic effects of the pandemic reach their peak.

\section{Conclusion - The Way Out}

There are several scenarios concerning how the situation may develop. The epidemic is expected to reach its peak in the first week of May in Hungary. According to officials, Hungary is prepared for it; it has the necessary medical facilities, equipment, and workforce. After one or two weeks with the accelerated spread of COVID-19, life can gradually be normalized, and we can get back to normal by mid- or late summer. Strict restrictions on movement are expected to be relaxed from May 4; together with some companies restarting manufacturing, school-leaving examinations will be arranged although only written exams will be organized with observing all rules of avoiding any possible transmission of the coronavirus. Hungary can gradually resume normal life both in terms of the economy and everyday life. Others predict that due to the flattened curve of the spread, this new coronavirus will stay with us for long, and we will suffer severe economic and social consequences hitting us more harshly than the medical consequences themselves. According to a third scenario, we will face a new wave, or even further waves of the pandemic, perhaps as early as this fall. No one knows what the future holds.

However, by working hard on finding an effective treatment for COVID-19, we can avoid the worst scenario. There are promising research efforts in various parts of the world, including Hungary. Even if we overcome the pandemic and the economic downturn and heal the social consequences, our life will not be the same as it used to be. I hope that we will learn the lesson well and come out of this difficult period with an enhanced sense of solidarity.

\section{Notes}

1. Eddy, K. (2020): Hungary's Economy and Coronavirus: Forecasting the Tempest. Budapest Business Journal. 28 (5) 3.

2. HungaryToday. (2020, April14) Retrived June 1, 2020 from https://hungarytoday.hu/imf-forecast-hungary-gdp-2020/

3. United Nations. Division of Economic Affairs.. Social Inclusion. (2020) Everyone Included: Social Impact of Covid19.The Social Impact of COVID19. Retrieved from https://www.un.org/development/desa/dspd/everyoneincluded-covid-19.html 


\section{References}

Caspar, K. (2020) Hungarian Startup Offers Help to EU Government. Budapest Business Journal. 28(6), 5.

Eddy, K. (2020) Hungary's Economy and Coronavirus: Forecasting the Tempest. Budapest Business Journal, 28(5), 3.

Gaal, B. (2020) Operating Telco Giant in the Time of COVID-19. Budapest Business Journal. 28 (7), 8.

Kiraly, I. (2020) Interview: Responding to the Coronavirus and Laying 5G Foundations. Budapest Business Journal. 28 (7), 11.

Marshall, R. (2020) Making the Coronavirus Statistics More Personal. Budapest Business Journal. 28 (7), 2.

Marshall, R. (2020) Coronavirus Response: Adaptation is a Condition of Survival. Budapest Business Journal. 28 (7), 5-6.

Morrell, G. (2020) Retail and Logistics Sectors Hardest hit by COVID-19. Budapest Business Journal. 28 (6), 13.

Morrell, G. (2020) "Need for Liquidity Apparent in Investment Markets," Budapest Business Journal. 28 (7), 4.

Nemethy, L. (2020) Coronavirus: Are Financial Markets out of the Woods? Budapest Business Journal. 28 (8), 7.

NguyenHuu, T. and D. D Karaman (2020) A new and benign hegemon on the horizon? The Chinese century and growth in the Global South. Economics: Keil . 14 (12), 1-34. http://www.economics-ejournal.org/economics/journalarticles/2020-12

Smyth, R. (2020) Wineries Battle to Come to Terms with Coronavirus' Economic Effect. Budapest Business Journal. 28 (7), 13.

Vegh, Z. (2020) Coronavirus a Further Threat to Weakening Forint. Budapest Business Journal. 28 (5), 16.

Welfens P. J. (2020) Macroeconomic and healthcare aspects of the coronavirus epidemic: EU, US and global perspectives. International Economics and Economic Policy, Heidelberg, 17 (2), 295-362. https://europepmc.org/article/pmc/pmc7245192 